\title{
Características, satisfacción vital y valores entre voluntarios en México. Evidencias de un proyecto educativo
}

\section{Characteristics, vital satisfaction and values among volunteers in Mexico. Evidences of an educational project}

DOI: https://doi.org// 0.32870/eees.v26i76.7093

Felipe J. Hevia Samana Vergara-Lope*

\section{Resumen}

Ante un creciente interés en promover la participación social en educación a través del trabajo voluntario, el presente artículo busca analizar las principales características, la satisfacción vital y los valores de ochocientos sesenta y ocho voluntarios que participaron en el proyecto Medición Independiente de Aprendizajes (MIA). El objetivo de dicha caracterización es pensar en estrategias para promover el trabajo voluntario como una vía para mejorar la educación y generar beneficios en las personas. Para analizar los resultados, se utilizaron métodos cualitativos y cuantitativos. Se concluye que los voluntarios de MIA son de tipo infrecuente, orientados a campañas, instrumentales y tienen altos niveles de satisfacción vital y valores personales. Se discute la necesidad de fomentar el trabajo voluntario y se destaca que la temática educativa tiene una fuerte capacidad de movilización.

Palabras clave: voluntariado, educación, satisfacción vital, valores sociales, participación comunitaria.

\begin{abstract}
Given a growing interest in promoting social participation in education through voluntary work, the aim of this article is to analyze the main characteristics, life satisfaction and values of eight hundred sixty eight volunteers who participated in the Independent Measurement of Learning project (MIA, by its initials in Spanish). The objective is to think about strategies to promote volunteer work as a way to improve education and raise personal benefits. To analyze the results, qualitative and quantitative methods were used.The results indicate that MIA volunteers are infrequent, oriented to campaigns, instrumental and have high levels of life satisfaction and personal values. The need to promote volunteer work is discussed and it is emphasized that the educational theme has a strong capacity for mobilization.
\end{abstract}

Keywords:Volunteering, education, social values, vital satisfaction, community participation.

\footnotetext{
- Profesor-Investigador del Centro de Investigaciones y Estudios Superiores en Antropología Social (CIESAS), unidad Golfo, México. ORCID: https://orcid.org/0000-0002-4424-5320

fhevia@ciesas.edu.mx

• Investigadora del Instituto de Investigaciones en Educación de la Universidad Veracruzana (Uv), México. ORCID: https://orcid.org/0000-000I-8029-3533

samanavergaralope@gmail.com

Fecha de recepción: I5 de marzo de 2019. Fecha de aceptación: 20 de junio de 2019.
} 


\section{Introducción}

Este artículo se genera a partir del desconocimiento sobre los perfiles de voluntarios que participan específicamente en proyectos educativos en México, en particular sobre sus características principales, grado de satisfacción vital y escala de valores.

Poder caracterizar a los voluntarios de un proyecto educativo permite pensar en estrategias para promover el trabajo voluntario como una vía para mejorar la educación y suscitar beneficios personales. Esto es, conocer las principales características de estos actores es pertinente para una agenda educativa que busque incorporar las acciones voluntarias y solidarias para enfrentar el rezago de aprendizajes y mejorar la educación; para una agenda política que examine las acciones voluntarias para poder promoverlas y reconocerlas; y para una agenda académica que pretenda aumentar el conocimiento acerca de los perfiles, los roles, beneficios y problemáticas relacionadas con los voluntarios en diferentes contextos y desde diversas aproximaciones disciplinares.

En efecto, como se revisará más adelante, el estudio de los voluntarios y las acciones voluntarias resulta pertinente en diversas agendas académicas, dentro y fuera de México. A nivel internacional, existe interés en la academia sobre el estudio del voluntariado dentro de disciplinas como sociología, ciencia política y estudios del desarrollo. Estas se interesan en el trabajo voluntario como expresión de la participación ciudadana y de la densidad asociativa en sociedades contemporáneas, especialmente en los análisis orientados a caracterizar a la sociedad civil y al tercer sector y analizar su participación en las esferas económica y de desarrollo.

En otras disciplinas, como la psicología, el estudio de los voluntarios resulta pertinente y relevante para la compren-

\section{6}


sión de diversos factores como motivación, valores y personalidad involucrados en las acciones voluntarias en diversos contextos, así como los potenciales efectos de dichos factores en la salud mental de los participantes (Wilson, 2012).

En México, el voluntariado como problema de investigación no es nuevo (Butcher, 2008b; Serna, 2010), y su estudio resulta pertinente para comprender las formas de relación sociedad-Estado-mercado en diversas escalas, a nivel tanto nacional (Centro Mexicano para la Filantropía, 2013) como regional (Mateo Pacheco, 2017; Muñoz y Vázquez, 2012), pues busca caracterizar el peso económico de las acciones solidarias, las redes de organizaciones civiles involucradas, las formas de interacción con agencias gubernamentales, sus aportes a la construcción de ciudadanía (Instituto Nacional Electoral, 2014), así como la necesidad de promover y reconocer su labor en cuerpos legales (García et al., 2010). Por ello, el estudio empírico de diversas experiencias de acción voluntaria resulta pertinente en México para comprender las potencialidades y límites respecto a las formas de socialidad y la construcción de relaciones sociedad-Estado que generan, esto para poder orientar la discusión pública hacia su reconocimiento y también hacia el fomento de acciones voluntarias.

Desde la esfera política, los estudios sobre las acciones voluntarias resultan pertinentes para generar y perfeccionar cuerpos legales que promuevan y reconozcan la acción voluntaria y para asegurar su involucramiento en la consecución exitosa de los Objetivos de Desarrollo Sostenible, promovidos por Naciones Unidas (Asamblea General de las Naciones Unidas, 2015).

Por último, conocer las características de los voluntarios mexicanos de un proyecto educativo resulta pertinente para la agenda educativa. En efecto, las acciones voluntarias se desarrollan en diversos campos, con énfasis en atención y cuidado a poblaciones vulnerables y en temáticas ligadas al 
desarrollo social. De ahí que estudiar campos específicos de políticas sociales, como la salud o la educación, resulte pertinente para comprender las generalidades y particularidades que se pueden encontrar según el contexto geográfico donde se estudie la acción voluntaria (Eliasoph, 2013). Ahora bien, el estudio de voluntarios resulta particularmente pertinente a la investigación educativa debido a la existencia de más proyectos que trabajan con voluntarios y el mayor interés respecto de las funciones y experiencias de voluntariados en educación (Banerjee et al., 2017; Khasanzyanova, 2017; Wilson, 2018).

\section{I.Antecedentes}

Como se comentaba, el voluntariado y la acción solidaria como problemas de investigación han recibido creciente interés en el análisis social. En este apartado, se revisan someramente tres agendas desde las cuales se ha estudiado el voluntariado: la agenda académica -con especial relevancia en las ciencias sociales y la psicología- la agenda política y la agenda educativa.

\section{I Agenda académica en el estudio}

del voluntariado en investigación social

En la literatura internacional, el estudio del voluntariado se ha abordado desde diversas disciplinas. Desde la sociología, se ha estudiado el voluntariado como una forma específica de participación ciudadana (Butcher, 2009; Colectivo IOE, 1990; Eliasoph, 2013), y como una forma de acción colectiva asociada a la densidad asociativa de las sociedades contemporáneas (Fernández, 2004; Gonçalves, Grzybovski, Mozzato, y Toebe, 2017; Rochester, Paine, Howlett, y Zimmeck, 2010).

Dentro de dicha agenda, se ha asociado el trabajo voluntario al denominado tercer sector, enfatizando el peso del tra- 
bajo voluntario en diversas economías (Bailón, Pérezgrueso, y Arceiz, 2017; Butcher, 2008b y 2014; Lewis, 1999) y sectores específicos, como el marketing o el turismo (Gallarza, 2014; Gallarza, Arteaga-Moreno, Servera-Francés, y FayosGardó, 2016). Dentro de la ciencia política y los estudios del desarrollo, el análisis del voluntariado se ha centrado en su caracterización conceptual, y se ha generado una amplia discusión sobre su definición y principales características (Cnaan, Handy, y Wadsworth, 1996; Haski-Leventhal et al., 2019; Izquieta y Callejo, 1999; Wilson, 2000), incluyendo sus estereotipos (Ho y O'Donoghue, 2014).

Aunque las definiciones sobre voluntariado son diversas, comparten cuatro componentes básicos: el concepto de libre albedrio, la ausencia de recompensas monetarias tangibles, una actividad realizada a través de organizaciones formales, y su realización con el propósito de ayudar a otros (Cnaan et al., 1996, p. 370). A estos componentes se puede añadir la importancia de los beneficios que brinda a terceros y a la gente que presta el servicio voluntario (Butcher, 2008a, pp. 32-33).

Hay otros ejemplos de definiciones que retoman estos componentes. Por ejemplo, el Instituto Nacional de Estadística y Geografía (INEGI) define al voluntario como formado por aquellos sujetos que "no reciben una remuneración por su labor, y que su participación no está obligada por algún tipo de reglamentación, como es el caso del servicio social" (Instituto Nacional de Estadística y Geografía, 2014, p. 3). De manera análoga, Gallarza y colaboradores proponen la siguiente definición: "El voluntariado comprende todas las actividades y servicios proporcionados sobre la base de voluntariedad, como trabajo no remunerado dentro del contexto de un negocio formal (público o privado) o una asociación" (Gallarza et al., 2016, pp. 47-48).

El énfasis en los segundos rasgos enlistados -la voluntariedad y el beneficio a terceros- se puede encontrar, por 
ejemplo, en García Roca (2001), quien afirma que "El voluntariado es una institución social que ha nacido al rescoldo de unos procesos históricos y unos cambios culturales, que se despliegan en prácticas individuales, en organizaciones solidarias y en movimientos sociales" (p. 15). Al respecto de esta definición, el contexto histórico, político, social y cultural donde el voluntariado se desenvuelve es vital para comprender sus características y límites, tal como Subirats (2001, p. 44) analiza para el caso español.

De igual forma, Wilson, por ejemplo, define el voluntariado como "cualquier actividad en la que se da tiempo libre para beneficiar a otra persona, grupo u organización" (Wilson, 2000, p. 215). En el mismo sentido se manifiestan Izquieta y Callejo al afirmar que

El prójimo, su sufrimiento, los problemas y las necesidades de distintos colectivos despiertan la sensibilidad de personas que se asocian voluntariamente [...] con la intención de cooperar a la solución o disminución de estas situaciones sin buscar una contraprestación externa. (Izquieta y Callejo, 1999, p. 95)

En el mismo sentido, Butcher escribe:

Los voluntarios son individuos que van más allá de los confines de su empleo remunerado y de sus responsabilidades normales para contribuir con tiempo y servicio a una causa no lucrativa en la creencia [de] que su actividad es beneficiosa para otros, al igual que satisfactoria para ellos mismos [...]. Voluntario/a: es la persona que por elección propia y sin recibir remuneración, aporta tiempo a una actividad que va más allá del ámbito familiar en el servicio a los demás para el beneficio de terceros y la sociedad en su conjunto. (Butcher, 2008a, pp. 36-37)

Sobre estas definiciones, se han construido diversas clasificaciones sobre el trabajo voluntario según su tipo, organización, frecuencia, propósito, etc. Una clasificación 
muy conocida la proporcionan los voluntarios de Naciones Unidas, que identifican cuatro grandes tipos de voluntariado: 1) ayuda mutua o autoayuda; 2) filantropía o servicios a terceros; 3) campañas y causas; y 4) participación y gobierno propio (Butcher, 2008a, pp. 33-34; Independent Sector y Voluntarios de las Naciones Unidas, 2001, p. 14). Dentro de estas distinciones, es importante identificar los propósitos o áreas a donde se dirigen estas acciones y que varían entre países, por ejemplo, el combate a la pobreza, la salud y la educación, etc. (Butcher y Verduzco, 2016).

Otra clasificación muy útil diferencia acciones voluntarias regulares y espontáneas: las primeras son organizadas por medio de asociaciones y agrupaciones ciudadanas, y las "actividades espontáneas o informales [son propias] de la expresión solidaria" (Butcher, 2008b, p. 30). En este sentido, la Encuesta Nacional de Solidaridad y Acción Voluntaria (ENSAV) refiere tres perfiles de voluntarios: intensos, típicos e infrecuentes, de acuerdo con el número de acciones que realizaron el año previo (Butcher y Verduzco, 2016).

Una tipología complementaria para el voluntariado se propone en Izquieta y Callejo (1999), quienes clasifican a los voluntarios altruistas, esto es, los que nacen en parte como una reacción a la tendencia al individualismo como característica de la modernidad tardía, reacción que se expresa en adhesión a organizaciones voluntarias, como la Cruz Roja u otras de autoayuda (Izquieta y Callejo, 1999, pp. 97-99).

Los tipos de voluntarios identificados son tres: instrumentales, expresivos y morales. Los primeros buscan experiencia y formación, utilizar el tiempo libre y ejercer la profesión. Los segundos son motivados por vivir nuevas experiencias, conocer a otras personas, el prestigio social y la terapia ocupacional. A los terceros los motiva la reciprocidad y la obligación moral. Los voluntarios instrumentales centran su acción en la actividad profesional, por lo que requieren capacitación técnica específica, y sus incentivos 
están relacionados con el aprendizaje y la experiencia profesional (Izquieta y Callejo, 1999, pp. 112-116).

\section{2 Estudios sobre voluntariado en México}

Ahora bien, la agenda de investigación en México es coherente con la agenda internacional. Existe un interés creciente en identificar las particularidades de las acciones voluntarias en México, considerando el contexto, problemáticas y perfiles de dicho país. Se considera que estas acciones "[...] aportan servicios básicos o los complementan de una manera importante[,] y ello se realiza ya sea bajo esquemas organizativos formales e informales[,] la mayor parte a través de esquemas grupales, aunque también tienen lugar acciones individuales" (Butcher y Verduzco, 2016, p. 118). Estas diferencias, incluso en cuanto a lo que se considera acción voluntaria o no, son las que pudieran explicar los resultados de las encuestas realizadas en el país.

Según la primera ENSAV, se pueden distinguir diversos tipos de voluntarios en México. Los voluntarios intensos declararon trabajar todos los días, y representaron el 8\%; los voluntarios típicos son constantes en el trabajo voluntario y participan en promedio treinta y cuatro días por ocho horas al día, y representaron el 32\% de la muestra de la encuesta; y los voluntarios infrecuentes dedican en promedio 1.7 días laborales al año al trabajo solidario (Butcher, 2014, p. 96; Verduzco, 2008, p. 85). Vecinos, Iglesia y escuela son los tres rubros de actividades que comprendieron al 76\% de los voluntarios infrecuentes (Verduzco, 2008, p. 89).

Para 2013, según los resultados de la segunda ENSAV, se estimaba que en México se realizaban ciento noventa y dos millones quinientas acciones voluntarias definidas de manera amplia como trabajo solidario, con mayor incidencia de zonas rurales y de la región sur del país, y con presencia activa de jóvenes (Centro Mexicano para la Filantropía, 2013, p. 1). Estos datos coinciden con la primera ENSAV, 
donde la región sur aparece como la más participativa, con un $78 \%$ de personas que afirmó realizar acciones solidarias (Verduzco, 2008, p. 69).

Para el 2016, la ENSAV reportó que el 83\% de los mexicanos mayores de quince años (más de setenta y cuatro millones de personas) respondió haber realizado una o más acciones voluntarias en el último año (Butcher y Verduzco, 2016). En México, el voluntariado se ha asociado históricamente con asociaciones religiosas y de ayuda a los necesitados, y ha tenido un sesgo clasista y de género (Serna, 2010, p. 143).

Sin embargo, según la ENSAV de 2016, la actividad solidaria realizada en porcentaje más alto en ese último año fue llevada a cabo de manera infrecuente, no formal y en escuelas, no en el campo religioso. Los voluntarios más frecuentes, en contraste, sí continúan teniendo el ámbito religioso como el primer espacio de acción (Butcher y Verduzco, 2016). Por otro lado, la cuenta satélite de INEGI sobre instituciones sin fines de lucro afirma que el 52\% de las personas que laboran en este tipo de organizaciones lo hace de manera voluntaria, lo que representa hasta el $85 \%$ de trabajo voluntario en el caso de iglesias. Así,

en 2012 cerca de 134000 personas colaboraron en organizaciones no lucrativas de México sin recibir remuneración alguna por sus actividades, trabajando al menos una hora a la semana. De estas[,] el 5.3\% se dedica a temáticas de enseñanza e investigación. (Instituto Nacional de Estadística y Geografía, 20I4, p. 4)

Ahora bien, estas encuestas muestran un panorama general de la acción voluntaria en México, pero no logran describir de manera más específica la satisfacción vital y la escala de valores que caracterizan a los voluntarios en México, lo que resulta fundamental para comprender mejor a los sujetos sociales que realizan acciones voluntarias. 
En una escala más regional, los estudios sobre voluntariado se han centrado en la descripción y análisis de problemáticas específicas, como las experiencias de voluntarios en albergues de migrantes en Jalisco (Hernández López y Valverde Hernández, 2018) o la alianza de organizaciones civiles que realizan acciones voluntarias en Puebla (Mateo Pacheco, 2017). Un trabajo particularmente útil para comprender los vínculos del voluntariado con las relaciones sociedad-Estado está en Muñoz y Vázquez (2012), quienes analizan cómo se manifiesta el trabajo voluntario como resultado de la interacción entre población indígena y diversas agencias gubernamentales, como la Comisión Nacional de Fomento Educativo (Conafe).

\section{3 La agenda académica en psicología}

El estudio del voluntariado también es relevante en el campo de la psicología. Esto es visible en la revisión que Wilson (2012) ofrece sobre la literatura respecto del voluntariado, y que organiza la discusión en tres áreas: antecedentes, experiencias de voluntariados y consecuencias.

La primera discute la importancia del contexto donde se llevan a cabo las acciones voluntarias, enfatizando el interés de la psicología en el estudio de los factores asociados al trabajo voluntario, lo que incluye las diversas motivaciones según el curso de vida, la satisfacción y el compromiso; la segunda describe experiencias de voluntariado en diversas áreas; y la tercera se centra en las consecuencias positivas para los voluntarios, en especial respecto a la salud física y mental.

$\mathrm{Al}$ respecto, en la literatura es posible encontrar discusiones respecto a la importancia de la empatía (Azzollini, Pupko, Becerra, y Vidal, 2017), la motivación y el altruismo (Piedimonte y Depaula, 2018), la satisfacción con el trabajo voluntario (Soto-Lagos, Constela, y Vergara, 2017) y la escala de valores asociada al perfil de los voluntarios 
(Ariza-Montes, Tirado-Valencia, y Fernández-Rodríguez, 2017). Es en estas discusiones donde se enmarca el interés de esta investigación por la satisfacción vital y los valores para caracterizar a los voluntarios.

\section{4 Satisfacción vital y voluntariado}

La satisfacción vital y el bienestar han mostrado tener relación con la acción voluntaria (Cabrera-Darias y Marrero-Quevedo, 2015): realizar actividades voluntarias ayuda a tener mayor satisfacción vital, y tener mayor satisfacción vital hace que las personas se involucren más en las acciones solidarias, por lo que se muestran como elementos que se refuerzan de manera mutua.

Sin embargo, las investigaciones empíricas al respecto son relativamente escasas. En México, Serna (2010) muestra que el trabajo voluntario se asocia con las preocupaciones sociales y con el peso formativo de la familia como el primer impulso para realizar acciones voluntarias, con un peso histórico del voluntariado femenino.

Investigaciones empíricas sobre voluntariado en jóvenes mexicanos de bachillerato y licenciatura muestran la relación existente entre bienestar social, altruismo y voluntariado (Espinosa Rodríguez, Mayoral Sánchez, y Laca Arocena, 2013, p. 91). Por otro lado, en investigaciones realizadas en España, se ha encontrado que las actividades del voluntariado

suele[n] llevarse a cabo por una actitud positiva que produce en las personas un grado más alto de satisfacción vital, alcanzada al ayudar a la gente $\mathrm{o}$ al servir a la sociedad [...] desde un punto de vista psicológico, todo esto redunda en un mayor bienestar personal y social. (Gallarza et al., 2016, p. 48) 


\section{5 Valores y voluntariado}

De igual manera, según la literatura analizada, las personas voluntarias no sólo son motivadas por su bienestar y satisfacción, sino también por sus valores. Millán (2013) refiere que no se puede hablar del voluntariado sin hablar de ética, compromiso y responsabilidad, que funcionan como elementos de unión. Pareciera entonces que los valores también se relacionan con la acción voluntaria en dos vías: por un lado, tener valores relacionados a lo social permite involucrarse más en actividades solidarias, pero además "el voluntariado proporciona experiencias que permiten desarrollar valores [...], habilidades, conocimientos y competencias, un compromiso, desarrollar una ética y una responsabilidad" (Millán, 2013, p. 13).

Según la caracterización que hacen Antolín, Oliva, Pertegal y López (2011), los valores sociales se refieren a los vinculados con el compromiso social, la prosocialidad, la justicia y la igualdad social, son positivos y se relacionan con una buena integración social y contribución positiva a la comunidad. Los valores personales se refieren a la integridad, honestidad y responsabilidad, y se relacionan con la seguridad y la fortaleza personal para conducirse con base en los propios principios. Por último, los valores individualistas hacen referencia al hedonismo y el reconocimiento social, y pueden ser considerados como contravalores (Antolín et al., 2011).

\section{6 Agenda política: reconocimiento legal \\ y promoción del voluntariado}

Junto con la agenda académica, es posible identificar una agenda más política que tiene que ver con el reconocimiento y la protección legal de las acciones voluntarias. El aporte de la acción y el trabajo voluntarios es amplio, y se puede apreciar en múltiples dimensiones. Según Naciones Unidas: 
Las actividades voluntarias son una expresión de la disposición y la capacidad de las personas para comprometerse libremente a ayudar a otros y a mejorar la sociedad[,] aunadas [a] un espíritu de reciprocidad. Aportan beneficios significativos a los individuos y las comunidades, $y$ nutren y mantienen una trama más rica y un sentido más fuerte de confianza mutua y cohesión. El voluntariado constituye un enorme depósito de cualificaciones, energía y conocimiento a nivel local que puede ayudar a los Gobiernos a llevar a cabo programas y políticas mejor orientadas, más eficientes, participativas y transparentes. (Naciones Unidas, 200I, §6)

En este mismo sentido, la Agenda 2030 incorpora explícitamente la importancia de los voluntarios para alcanzar los Objetivos de Desarrollo Sostenible. Según la declaración de la Asamblea de Naciones Unidas,

las actividades voluntarias pueden pasar a ser otro poderoso medio para la aplicación de la agenda en distintos sectores. Las actividades voluntarias pueden contribuir a ampliar y movilizar a las sociedades y lograr la participación de las personas en la planificación y la aplicación de los objetivos de desarrollo sostenible a nivel nacional. (Asamblea General de las Naciones Unidas, 2015, p. 32)

La importancia y la búsqueda de reconocimiento del voluntariado poseen una larga tradición en Europa. Así, por ejemplo, existen diversas leyes para proteger y promover el voluntariado en Inglaterra (Rochester et al., 2010, p. 1) y España (Colectivo IOE, 2002; Ruiz, 2016).

Para el caso mexicano, en general se aprecia poco reconocimiento legal de las acciones voluntarias en términos específicos. A nivel federal no existe como tal una ley de voluntariado, aunque las acciones voluntarias se promueven y reconocen en diversos cuerpos legales, como en las leyes generales de Desarrollo Social, Seguridad Pública y Protección Civil, entre otras (Pérez, 2015). A nivel estatal, 
sólo se encuentra información respecto a una iniciativa de Ley de Voluntariado en el estado de Querétaro, que había sido aprobada en comisiones en 2017 (Legislatura Querétaro, 2017).

\section{7 Agenda educativa: participación} ciudadana para mejorar la educación

Por último, es posible identificar al interior de la agenda educativa un interés por el trabajo voluntario como forma de participación social en educación, tal como lo muestra la tercera ENSAV (Butcher y Verduzco, 2016).

A nivel internacional, existe una creciente literatura respecto al involucramiento de ciudadanos en la mejora educativa por medio de acciones voluntarias para incentivar aprendizajes básicos llevados a cabo en diversos países del sur global agrupados bajo la idea de evaluaciones dirigidas por ciudadanos (Citizen-Led Assessments) (Wilson, 2018).

Así, la investigación educativa se ha enfocado a analizar algunos programas educativos, como Read India (Dutt, Kwauk, y Robinson, 2016), o evaluaciones ciudadanas en diversos países de África (Munene, 2016), con la activa participación de voluntarios (Alcott, Rose, Sabates, Luisa Alonso, y Cherfils, 2018). En México, si bien existen trabajos relativos a la participación social en educación que discuten la importancia de la incorporación de ciudadanos en esta (Zurita, 2013), no se encuentran trabajos respecto a la participación de voluntarios en proyectos educativos.

\section{Objetivos del artículo y preguntas de investigación}

Tomando en cuenta estos antecedentes, el propósito de este artículo es aportar información sobre los sujetos que realizan acciones voluntarias. Son dos los objetivos: analizar las principales características de los voluntarios de un proyecto educativo en México, incluyendo la satisfacción vital 
y la escala de valores; y discutir algunos elementos para la promoción del voluntariado en dicho país.

Se seleccionó un proyecto educativo debido a la importancia que tiene el trabajo voluntario en la agenda educativa revisada arriba, pero también porque las acciones voluntarias relacionadas con la escuela, según la ENSAV, son muy importantes.

Las preguntas de investigación que guían este artículo son: ¿qué tipo de voluntarios participan en un proyecto educativo? ¿Qué características tienen? ¿Cuáles son sus grados de satisfacción vital y valores? ¿Existen diferencias entre el tipo de valores y la satisfacción vital entre los voluntarios? ¿Cómo se puede promover el voluntariado teniendo en cuenta sus particularidades y rasgos distintivos? Estas preguntas se consideran relevantes debido a la escasez de estudios que describan con datos empíricos las principales características de voluntarios, específicamente en términos de su satisfacción vital y escala de valores.

\section{Metodología}

Para responder las preguntas señaladas, se optó por una metodología mixta, basada en un estudio de caso. El caso seleccionado fue el proyecto Medición Independiente de Aprendizajes (MIA), que es desarrollado por el Centro de Investigaciones y Estudios Superiores en Antropología Social (CIESAS) y la Universidad Veracruzana (Uv), y en el marco del cual se llevan a cabo evaluaciones ciudadanas de aprendizajes. Se seleccionó este caso por la cantidad de voluntarios con que trabaja el proyecto (cerca de 2400 voluntarios entre 2014 y 2018), por la ausencia de información respecto a acciones voluntarias en educación, y por conveniencia, pues es un proyecto coordinado por los autores del presente artículo. Este caso permite adentrarse de manera más específica en las agendas académica, política 
y educativa identificadas arriba, y precisar sus particularidades, potencialidades y limitaciones.

El proyecto MIA, en la etapa de medición, implica reclutar y capacitar a ciudadanos voluntarios para que puedan aplicar una serie de instrumentos de medición a niños de entre cinco y dieciséis años en sus hogares, en una muestra representativa de estos. Como se detallará, el voluntariado MIA está conformado por hombres y mujeres, principalmente mayores de dieciocho años, interesados en la educación y que dedican un fin de semana para visitar los hogares y entrevistar a los padres de familia o cuidadores y a los niños y niñas. Los voluntarios que están interesados en participar reciben una capacitación de ocho horas sobre el modo de selección de hogares y aplicación de los instrumentos, y deben entrevistar quince hogares de una sección geográfica específica el sábado o domingo que realizan el trabajo de campo.

\section{I Muestra de estudio}

Se utilizó una muestra intencional por conveniencia, con la participación de ochocientos sesenta y ocho voluntarios que estuvieron en las mediciones de 2015 y 2016 en los estados de Campeche, Tabasco y Veracruz, y a los que se aplicaron instrumentos cualitativos y cuantitativos.

De los ochocientos sesenta y ocho voluntarios, sesenta eran de Campeche (6.9\%), ciento ochenta de Tabasco (20.7\%) y seiscientos veintiocho de Veracruz (72.4\%). Las edades de los voluntarios se ubicaron entre los quince y setenta y un años, con una media de 24.71 (DE=8.09); el 61.8\% de los voluntarios tenía entre diecinueve y veintitrés años. El $69.1 \%$ estaba formado por mujeres y el $30.9 \%$ por hombres. El $82.5 \%$ de los voluntarios que respondieron tenía escolaridad de licenciatura (Tabla 1 ). 
Características, satisfacción vital y valores entre voluntarios en México. Evidencias de un proyecto educativo

\begin{tabular}{lccc}
\multicolumn{4}{c}{ Tabla } \\
\multicolumn{1}{c}{ 1. Escolaridad de los voluntarios participantes } \\
$\quad$ Escolaridad & Frecuencia & Porcentaje & Porcentaje válido \\
Primaria & 1 & .1 & .1 \\
Secundaria & 16 & 1.8 & 2.0 \\
Preparatoria & 102 & 11.8 & 12.6 \\
Licenciatura & 668 & 77.0 & 82.5 \\
Posgrado & 23 & 2.6 & 2.8 \\
Subtotal & 810 & 93.3 & 100.0 \\
No respondieron & 58 & 6.7 & \\
Total & 868 & 100 & \\
\hline
\end{tabular}

Fuente: elaboración propia con datos de la investigación.

El estado civil de los participantes fue principalmente soltero $(78.1 \%$; $=632)$, seguido de casado $(18.5 \%$; $=152)$ y separado $(2 \% ; \mathrm{N}=16)$.

En términos de ocupación, casi dos de cada tres voluntarios eran estudiantes universitarios. Por la facilidad de los investigadores de integrarse, desde la uv y otras instituciones de educación superior, a las universidades, y por las capacidades requeridas de los voluntarios, se puede entender que la mayoría de los voluntarios estuviera formada por estudiantes. Sin embargo, también participaron empleados y personas en búsqueda de trabajo (Tabla 2).

\section{Tabla 2. Ocupación de la muestra}

\begin{tabular}{lcc}
\multicolumn{1}{c}{ Ocupación } & Frecuencia & Porcentaje válido \\
Empleo tiempo completo & 71 & 8.7 \\
Empleo medio tiempo & 83 & 10.2 \\
Desempleado, en busca de trabajo & 85 & 10.4 \\
Desempleado, no busca trabajo & 4 & .5 \\
Retirado & 12 & 1.5 \\
Estudiante & 561 & 68.8 \\
Total & 816 & 100 \\
\hline
\end{tabular}

Fuente: elaboración propia con datos de la investigación.

Sociedad No.76 
Por otro lado, el 76\% dijo que sí le interesaría volver a ser voluntario, principalmente por las experiencias personales $(64.9 \%)$ y por experiencia profesional (25.5\%).

\section{2 Descripción de instrumentos}

A los participantes voluntarios, MIA les aplicó un cuestionario posterior a su experiencia de trabajo de campo con tres apartados. El primero fue sobre información sociodemográfica. El segundo fue un apartado cualitativo, y consistió en un cuestionario autoaplicado de preguntas abiertas. Las preguntas fueron relacionadas con el trabajo realizado (¿cómo respondió la gente que visitaste? ¿Qué reacciones tenía?), con la capacitación recibida (¿consideras que la capacitación que recibiste como voluntario fue suficiente para el trabajo de campo? ¿Qué faltó en la capacitación?), con sus experiencias (después de vivir la experiencia, ¿qué sugerencias tienes para mejorar el proyecto?), y sus aprendizajes (desde el plano académico o laboral, ¿qué te deja MIA como aprendizaje? ¿Te interesaría volver a ser voluntario? ¿Por qué?). El tercero fue un apartado cuantitativo e incluyó dos instrumentos, uno sobre escala de valores y otro sobre satisfacción vital.

Se utilizó la escala para la evaluación de la satisfacción vital, creada por Huebner (1991) para una muestra de adolescentes españoles de doce años en adelante. La versión original cuenta con siete reactivos y siete opciones de respuesta que van de totalmente en desacuerdo a totalmente de acuerdo. El alfa reportada por los autores es de .81. Para utilizar el instrumento en la presente muestra, se cambiaron de siete a cuatro las opciones de respuesta, y se obtuvo un alfa total con siete reactivos de $.734(\mathrm{~N}=868)$ (Huebner, 1991).

El instrumento escala de valores para el desarrollo positivo adolescente (EV-DPA) fue desarrollado por Antolín et al. (2011) para medir adolescentes españoles de doce a dieci- 
siete años. El instrumento original cuenta con veinticuatro reactivos, tres factores y ocho dimensiones que se responden con siete opciones de respuesta, que van de nada importante a lo más importante. Las alfas que obtuvieron los autores del instrumento son: valores sociales=.89; valores personales $=.89$; valore individualistas $=.80$; prosocialidad $=.90$; compromiso social=.90; justicia e igualdad social=.86; integridad $=.84$; responsabilidad $=.87$; honestidad $=.87$; hedonismo $=.84$; reconocimiento social $=.89$.

En esta investigación, se cambiaron las opciones de respuesta de siete a cuatro (de nada importante a muy importante), y se obtuvieron alfas para la muestra de sujetos mexicanos de edades entre quince y setenta y un años. Las alfas totales y por factor fueron aceptables, como se muestra en la Tabla 3.

Tabla 3. Alfa total y por factores y dimensiones para la EV-DPA Escala Alfa de Cronbach No. de elementos $\quad N$

Factores

$\begin{array}{llll}\text { Valores sociales } & .858 & 9 & 868\end{array}$

$\begin{array}{llll}\text { Valores personales } & .750 & 9 & 868\end{array}$

$\begin{array}{llll}\text { Valores individualistas } & .776 & 6 & 868\end{array}$

Dimensiones

Prosocialidad $\quad .732$

$801-3-868$

Compromiso social $\quad .801$

868

Justicia e igualdad social $\quad .704$

$\begin{array}{lll}.537 & 3 & 868\end{array}$

Integridad

Responsabilidad $\quad .595$

868

Honestidad

.679

868

Hedonismo

.692

868

Reconocimiento social

.810

868

Total

.850

868

Fuente: elaboración propia con datos de la investigación. 


\section{Procedimientos}

Las respuestas se codificaron y sistematizaron en una base de datos. La información de las preguntas abiertas se analizó con métodos cualitativos, con el software Nvivo 11 y mediante análisis estructural de discurso, buscando caracterizar códigos significativos y su tipo de valoración y estructura (Martinic, 2006; Suárez, 2008), así como generar análisis de contenido semántico para identificar las principales representaciones culturales inmersas en los discursos sociales expresados en las respuestas abiertas de los cuestionarios.

Los códigos generados fueron experiencias, aprendizajes y valoración. El análisis cualitativo se centró en las representaciones positivas y negativas respecto de las experiencias de los voluntarios, así como en identificar la importancia de la experiencia y capacidad de la temática educativa como agentes motivadores para el trabajo voluntario en el caso seleccionado.

Para el análisis cuantitativo, se utilizó el software spss20 y se usaron operaciones descriptivas e inferenciales, así como diversos procedimientos de diferenciación -como $t$ de Student- y correlaciones -como la correlación de Spearman-.

\section{Resultados}

El resultado principal de la investigación es que el perfil de los voluntarios de MIA se puede definir como infrecuente, orientado a campañas, instrumental, con altos niveles de satisfacción vital y con prevalencia de valores personales.

\section{I Frecuencia de la actividad voluntaria: infrecuentes}

Respecto a la frecuencia de la actividad voluntaria, los voluntarios que participan en el proyecto MIA se caracte- 
rizan como infrecuentes pues dedican menos de 1.7 días laborales al año al trabajo solidario (Butcher, 2014, p. 96; Verduzco, 2008, p. 85). La acción voluntaria en MIA implica dieciséis horas: ocho para capacitarse en la aplicación de los instrumentos y ocho para trabajo de campo. La limitación temporal y de funciones son circunstancias valoradas positivamente por los voluntarios de MIA. En las narraciones es posible ver que, para los voluntarios, resulta un atractivo la oferta de participar en una actividad limitada en tiempo, con un propósito claro y con instrucciones precisas: capacitarse en la aplicación de encuestas y recolectar información sobre un número limitado de hogares, seleccionados de manera sistemática, en una sección específica de su misma localidad o cercana a ella.

\section{2 Formas de voluntariado: participación en campañas y causas}

Respecto al tipo de voluntariado que realizan, los voluntarios de MIA se ubican en el tipo de participación en campañas y causas (Butcher, 2008a, pp. 33-34; Independent Sector y Voluntarios de las Naciones Unidas, 2001, p. 14), en este caso en temáticas educativas.

Al respecto, en los relatos es frecuente la valoración positiva del trabajo voluntario en temas educativos, más al comprender los rezagos de aprendizajes que los voluntarios encuentran en los hogares. En ese sentido, algunas respuestas ante la pregunta "¿Cuáles fueron tus principales aprendizajes como voluntario de MIA?" fueron:

- "Conocer el nivel de aprendizaje que tienen los niños y conocer el trabajo de los docentes" (mujer, estudiante, diecinueve años, Chicontepec);

- "Que está algo insuficiente la educación en Veracruz y eso afecta a los niños, y que deberíamos hacer algo para capacitar más a los docentes, para tener una 
mejor calidad" (mujer, estudiante, veintiún años, Veracruz-puerto);

- "La importancia de descubrir los niveles de aprendizaje en las materias de lectura y matemáticas, ya que hay carencias de conocimiento en los niños" (mujer, estudiante, veintidós años, Boca del Río);

- "Ver a la sociedad, que en cuestión de educación no participa, y que los pequeños tienen deficiencias" (hombre, estudiante, veinticinco años, Poza Rica).

El conocimiento sobre la forma de vida de los niños y los problemas educativos relacionados con los hogares también formaron parte de esta narrativa positiva sobre la experiencia que significó participar como voluntario. Así, los voluntarios expresaban:

- "Mi aprendizaje fue que a pesar de cómo vivan las personas y también de la economía [...] no les importa cuánto gastar, sino mandar a sus hijos a la escuela" (mujer, estudiante, dieciocho años, Tuxpan);

- "El trabajo de campo, conocer la situación de los niños" (mujer, estudiante, veintiún años, Boca del Río);

- "Me di cuenta de las condiciones en las que está la educación de infantes, y quisiera buscar una solución a todo eso" (mujer, estudiante, veintiún años, Fortín de las Flores).

Los voluntarios enfatizan la utilidad para su formación y experiencia, pero desde una visión más cooperativa que busca aportar con su trabajo a mejorar la educación en sus comunidades.

\subsection{Tipo de voluntariado: instrumental}

De igual manera, se puede clasificar a los voluntarios de MIA como instrumentales, bajo la clasificación de Izquieta y Callejo (1999, pp. 112-116), puesto que sus motivaciones se 
orientan a la búsqueda de nuevas experiencias y formación, ocupar el tiempo libre y ejercer la profesión. Como ya se dijo, los voluntarios instrumentales centran su acción en la actividad profesional, por lo que requieren capacitación técnica específica, y sus incentivos están relacionados con el aprendizaje y la experiencia profesional.

Como muestra la Figura 1, al preguntar a los voluntarios sobre sus principales aprendizajes, la frecuencia de conceptos se centró, por un lado, en la experiencia, y, por otro lado, en la importancia de incidir en temas educativos. Así, en un recuento de las palabras más utilizadas entre los voluntarios sobresalen los conceptos experiencia, educación, aprendizaje y conocimientos como los más frecuentes.

Figura 1. Recuento de palabras sobre aprendizajes de voluntarios. Quince términos más frecuentes

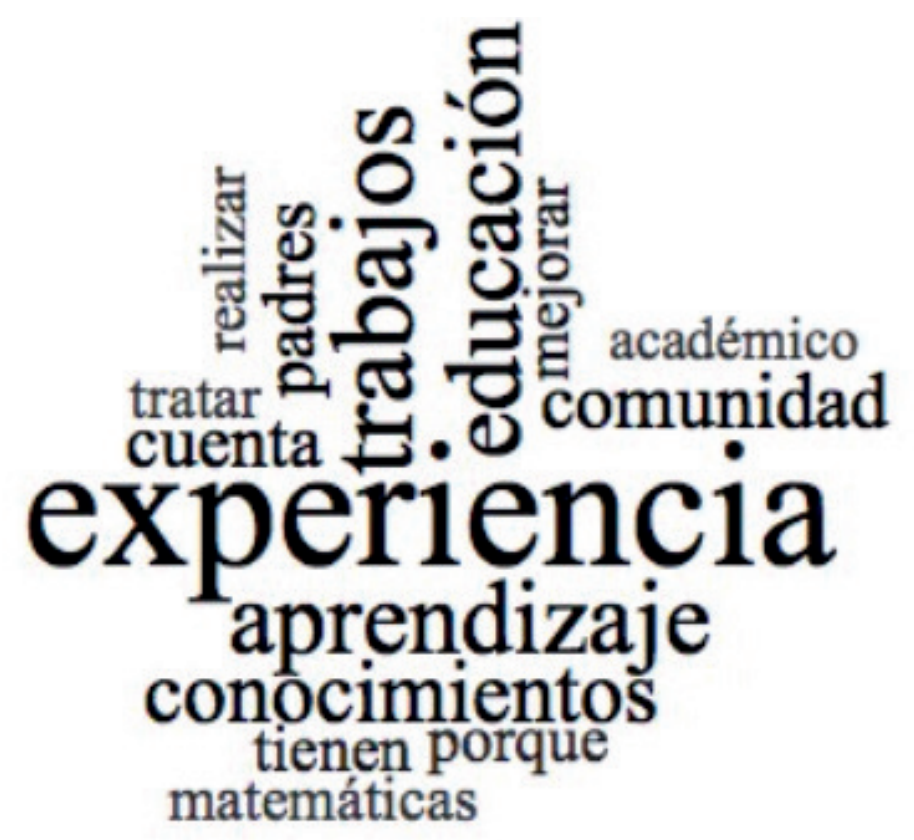

Fuente: elaboración propia con datos de la investigación.

En este sentido, los voluntarios enfatizan como algo positivo tener una nueva experiencia; específicamente, valoraron 
conocer nuevas realidades e interactuar con padres y niños en sus hogares. Algunos ejemplos de respuestas al respecto son las siguientes:

- "Es una experiencia para estar en contacto tanto con los niños y padres para mejorar su aprendizaje" (mujer, ama de casa, cincuenta y cinco años, Pánuco);

- "Prácticamente es una experiencia más para mí, y pues me queda la satisfacción de que las familias me recibieron amablemente y colaboraron para llevar a cabo este piloteo" (mujer, licenciada en gestión intercultural, treinta y cuatro años, Ixhuatlán de Madero);

- "Me deja una experiencia que sólo se vive en campo y que nos ayuda a interactuar con padres de familia y saber los aportes sobre la educación de los hijos. Creo importante que se realicen actividades de intervención como las estrategias para mejorar la educación de nuestro país" (mujer, egresada en gestión intercultural, veintidós años, Chicontepec).

La experiencia formativa para los voluntarios estudiantes universitarios también aparece en las narrativas positivas de la experiencia:

- "Un aprendizaje significativo, tener más confianza y persuasión en las personas y en mí misma. Que me ayudó a mi formación como psicóloga" (mujer, psicóloga, veintidós años, Veracruz-puerto);

- "Me deja la satisfacción de enseñanza y de ampliar los retos que se nos encomienden" (mujer, auxiliar administrativa, treinta y cinco años, Pánuco).

Dado que se trata de voluntarios instrumentales, como ya se dijo, muchos de ellos que son estudiantes universitarios de carreras afines a la educación -como pedagogía, maestro normalista o psicología- expresaron una intención clara de poder formarse en investigación, situación que muchas 
veces está lejos de los procesos formativos en licenciatura. La edad y ocupación de los voluntarios de MIA, jóvenes estudiantes en su mayoría, facilitan su motivación en torno a ganar experiencia y aprender, además de que les permiten participar en un proyecto que tiene fines nobles pues se enfoca en educación.

\section{4 Niveles de satisfacción vital: altos}

Los resultados muestran altos niveles de satisfacción vital entre los sujetos entrevistados. Más del 90\% de los voluntarios respondió que su vida va bien y que llevan una buena vida (opciones de acuerdo y totalmente de acuerdo); arriba del 80\% reveló estar en desacuerdo o totalmente en desacuerdo respecto a que su vida no es demasiado buena; sin embargo, estos porcentajes bajan cuando se trata de compararse con los contemporáneos: cerca del 40\% dice que su vida no es mejor que la de la mayoría de la gente de su edad, y el $46.6 \%$ estaría de acuerdo en cambiar muchas cosas de su vida (Tabla 4).

En la Tabla 4 se pueden observar las medias de los reactivos. El reactivo que más se respondió con satisfacción vital fue "mi vida va bien". De esta forma, se puede concluir que se observa alta satisfacción vital. 
Felipe J. Hevia y Samana Vergara-Lope

Tabla 4. Porcentajes por opción de respuesta de reactivos de satisfacción vital y medias por reactivo

\begin{tabular}{|c|c|c|c|c|c|}
\hline & $\begin{array}{c}\text { Total } \\
\text { desacuerdo }\end{array}$ & Desacuerdo & $\begin{array}{c}\text { De } \\
\text { acuerdo }\end{array}$ & $\begin{array}{c}\text { Total } \\
\text { acuerdo }\end{array}$ & $M(D E)$ \\
\hline $\begin{array}{l}\text { 1. Mi vida va } \\
\text { bien }\end{array}$ & $2.6 \%$ & $3.3 \%$ & $44.9 \%$ & $49.3 \%$ & $3.41(.679)$ \\
\hline $\begin{array}{l}\text { 5. Llevo una } \\
\text { buena vida }\end{array}$ & $1.1 \%$ & $8.1 \%$ & $45.1 \%$ & $45.6 \%$ & $3.35(.678)$ \\
\hline $\begin{array}{l}\text { 6. Tengo lo } \\
\text { que quiero en } \\
\text { la vida }\end{array}$ & $2.8 \%$ & $15.8 \%$ & $49.9 \%$ & $31.5 \%$ & $3.10(.760)$ \\
\hline $\begin{array}{l}\text { 7. Mi vida es } \\
\text { mejor que la } \\
\text { de la mayoría } \\
\text { de la gente de } \\
\text { mi edad }\end{array}$ & $9.6 \%$ & $30.2 \%$ & $41.5 \%$ & $18.7 \%$ & $2.69(.883)$ \\
\hline $\begin{array}{l}\text { 2. Mi vida no } \\
\text { es demasiado } \\
\text { buena }\end{array}$ & $3.6 \%$ & $12.9 \%$ & $35.2 \%$ & $48.3 \%$ & $3.28(.822)$ \\
\hline $\begin{array}{l}\text { 3. Me } \\
\text { gustaría } \\
\text { cambiar } \\
\text { muchas cosas } \\
\text { de mi vida }\end{array}$ & $15.2 \%$ & $31.2 \%$ & $31.4 \%$ & $22.2 \%$ & $2.61(.994)$ \\
\hline $\begin{array}{l}\text { 4. Ojalá } \\
\text { tuviera una } \\
\text { vida distinta }\end{array}$ & $6.9 \%$ & $12.6 \%$ & $32.6 \%$ & $48.0 \%$ & $3.22(.913)$ \\
\hline
\end{tabular}

Fuente: elaboración propia con datos de la investigación.

Por otro lado, al analizar algunas diferencias entre las características de los sujetos y sus grados de satisfacción vital, la edad no se correlacionó de manera significativa con la satisfacción vital. Tampoco se encuentran diferencias significativas cuando se hacen comparaciones por sexo en todos los reactivos y la sumatoria, con excepción del reactivo "ojalá tuviera una vida distinta", en el cual los hombres muestran significativamente menor satisfacción de su vida $(\mathrm{t}=3.485$, sig. al .001, gl=677).

\section{0}


Donde sí se encontraron diferencias estadísticamente significativas fue en las variables escolaridad (Tabla 5) y ocupación (Tabla 6). Respecto de la escolaridad, se encontró una correlación de Spearman positiva, muy baja, pero también significativa (Rho=.122, sig. al .01), esto es, a mayor escolaridad mayor la satisfacción vital.

Tabla 5. Medias de satisfacción vital por escolaridad

$\begin{array}{llrl}\text { Escolaridad } & \text { Med } & N & D E \\ \text { Primaria } & 14.00 & 1 & \\ \text { Secundaria } & 18.93 & 15 & 3.807 \\ \text { Preparatoria } & 21.01 & 85 & 3.469 \\ \text { Licenciatura } & 21.82 & 541 & 3.556 \\ \text { Posgrado } & 22.26 & 19 & 3.784 \\ \text { Total } & 21.65 & 661 & 3.595 \\ & \mathbf{F = 4 . 4 8 7 *} \text { gl=4 } & \\ \text { *p }<.001 . & \end{array}$

Fuente: elaboración propia con datos de la investigación.

Por ocupación, se encontraron diferencias estadísticamente significativas. En la Tabla 6, las medias se muestran ordenadas de mayor a menor, con los retirados como el grupo que tiene las mayores medias de satisfacción vital.

Tabla 6. Medias de satisfacción vital por ocupación

\begin{tabular}{lcrc}
\multicolumn{1}{c}{ Ocupación } & Media & \multicolumn{1}{c}{$N$} & DE \\
Retirado & 22.82 & 11 & 5.492 \\
Empleo tiempo completo & 22.07 & 54 & 3.776 \\
Empleo medio tiempo & 21.78 & 64 & 3.364 \\
Estudiante & 21.76 & 463 & 3.463 \\
Desempleado, no busco trabajo & 20.25 & 4 & 3.202 \\
Desempleado, en busca de trabajo & 20.10 & 67 & 3.955 \\
Total & 21.63 & 663 & 3.598 \\
& & & \\
* $\mathbf{p}=\mathbf{3 . 1 1 5 *}$; $\mathbf{g l}=\mathbf{5}$ & & \\
\hline
\end{tabular}

Fuente: elaboración propia con datos de la investigación.

Sociedad No.76 
5. 5 Escala de valores: prevalencia de valores personales

En relación con los valores, la muestra presenta una prevalencia de valores personales, seguidos de los sociales e individualistas (Tabla 7). Con respecto a las dimensiones, la media más alta se presenta en honestidad y la más baja en reconocimiento social.

Tabla 7. Medias y medias ponderadas por factor y dimensión de la escala de valores

\begin{tabular}{|c|c|c|c|c|c|c|c|c|}
\hline ర్త & Media & $D E$ & $R$ & $M / R$ & Dimensiones & Media & $D E$ & Reactivos \\
\hline \multirow{3}{*}{ 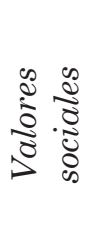 } & \multirow{3}{*}{30.06} & \multirow{3}{*}{4.18} & \multirow{3}{*}{9} & \multirow{3}{*}{3.34} & Prosocialidad & 9.67 & 1.719 & $7,8,16$ \\
\hline & & & & & $\begin{array}{l}\text { Compromiso } \\
\text { social }\end{array}$ & 9.77 & 1.833 & $5,6,12$ \\
\hline & & & & & $\begin{array}{l}\text { Justicia e } \\
\text { igualdad social }\end{array}$ & 10.63 & 1.446 & $4,10,11$ \\
\hline \multirow{3}{*}{ 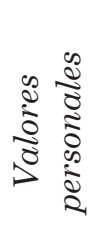 } & \multirow[b]{3}{*}{31.42} & \multirow[b]{3}{*}{3.54} & \multirow[b]{3}{*}{9} & \multirow[b]{3}{*}{3.49} & Responsabilidad & 10.62 & 1.532 & $1,20,21$ \\
\hline & & & & & Integridad & 9.85 & 1.710 & $14,22,24$ \\
\hline & & & & & Honestidad & 10.94 & 1.304 & $9,17,18$ \\
\hline \multirow{2}{*}{ 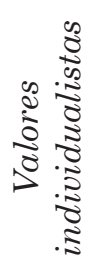 } & \multirow[b]{2}{*}{15.04} & \multirow[b]{2}{*}{3.83} & \multirow[b]{2}{*}{6} & \multirow[b]{2}{*}{2.51} & Hedonismo & 8.26 & 2.218 & $13,15,23$ \\
\hline & & & & & $\begin{array}{l}\text { Reconocimiento } \\
\text { social }\end{array}$ & 6.82 & 2.343 & $2,3,19$ \\
\hline
\end{tabular}

Nota: $\mathrm{M} / \mathrm{R}=$ media entre el número de reactivos.

Fuente: elaboración propia con datos de la investigación.

Los reactivos del instrumento se encuentran detallados en la Tabla 8. Se puede observar que las dos preguntas que obtienen las medias más altas están relacionadas a la dimensión honestidad. Por su parte, las medias más bajas corresponden a reactivos relacionados con las dimensiones de reconocimiento social y hedonismo.

\section{2}




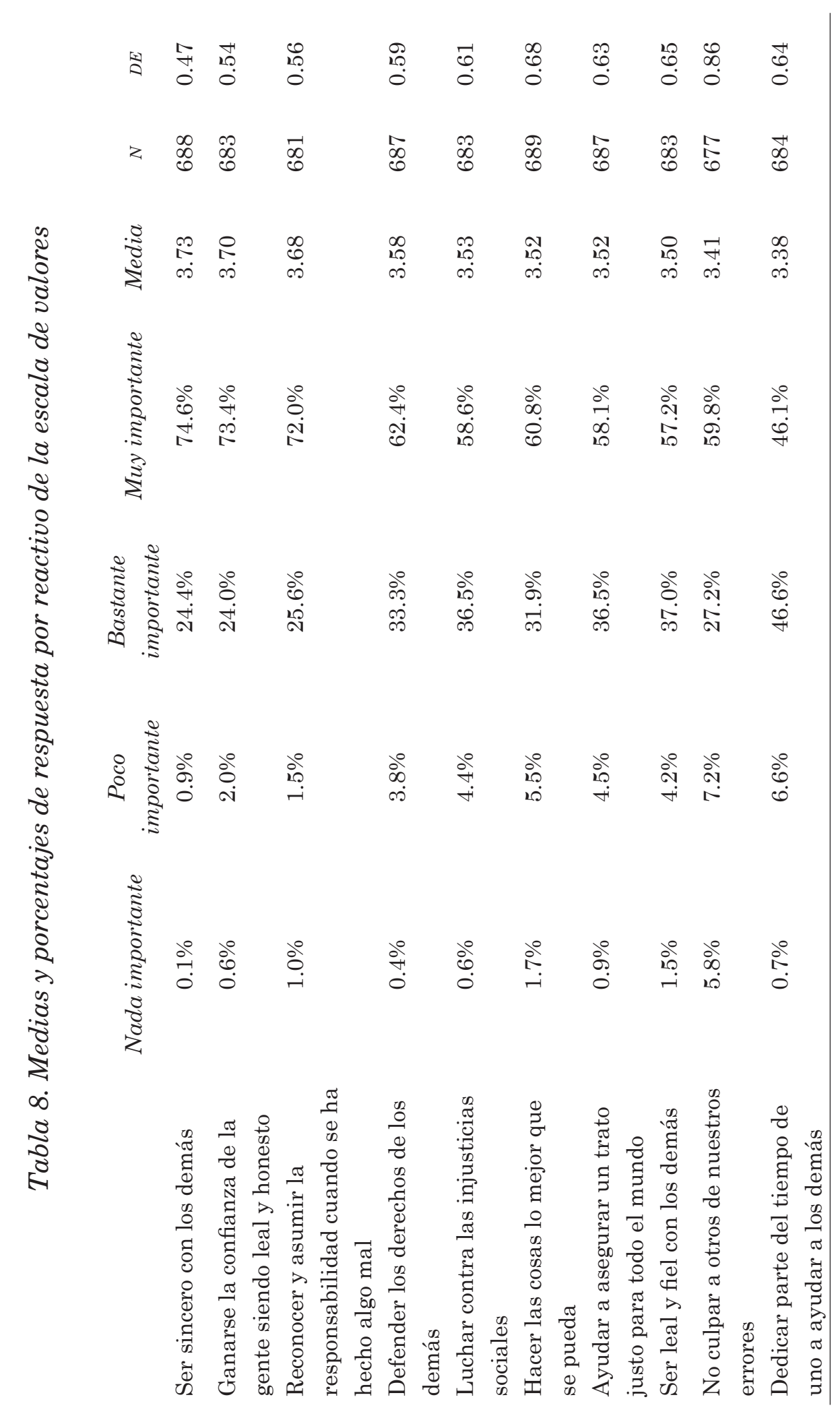

Sociedad No.76 
Felipe J. Hevia y Samana Vergara-Lope

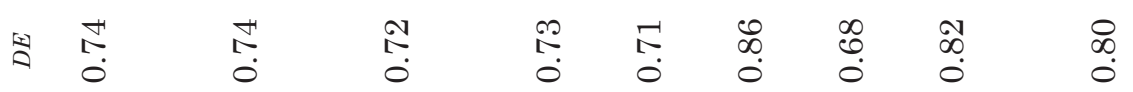

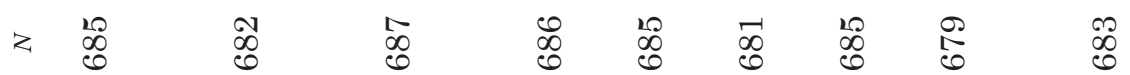

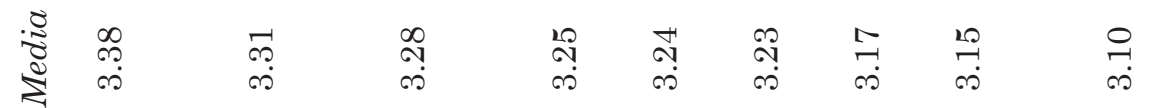

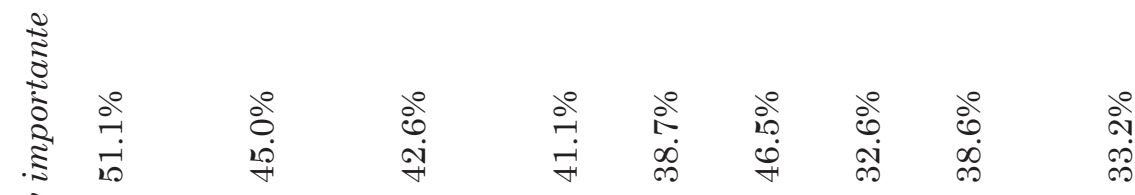

$$
\begin{aligned}
& \text { इ }
\end{aligned}
$$

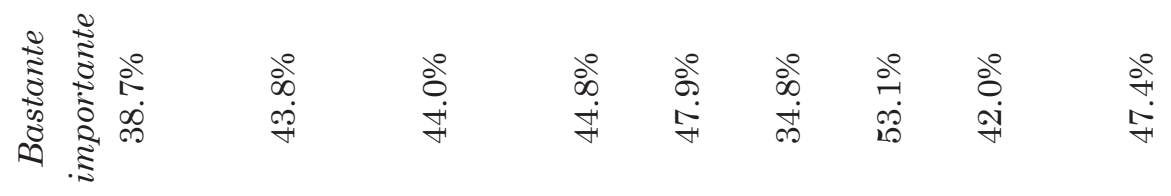

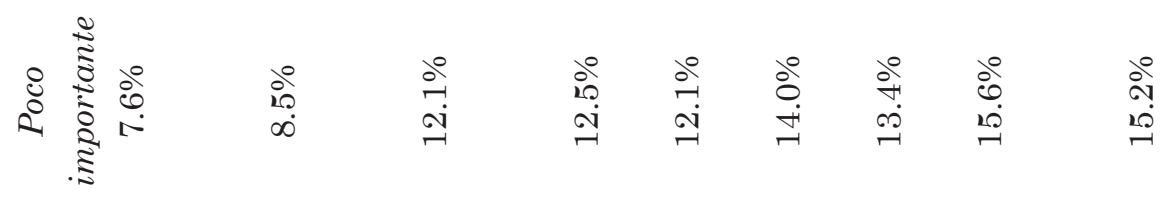

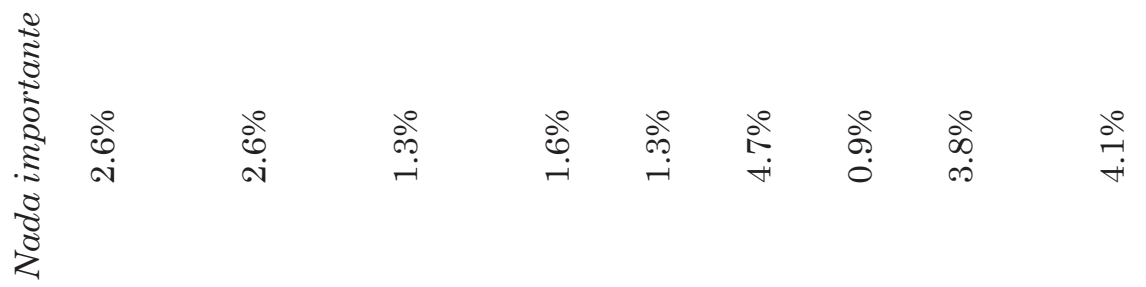

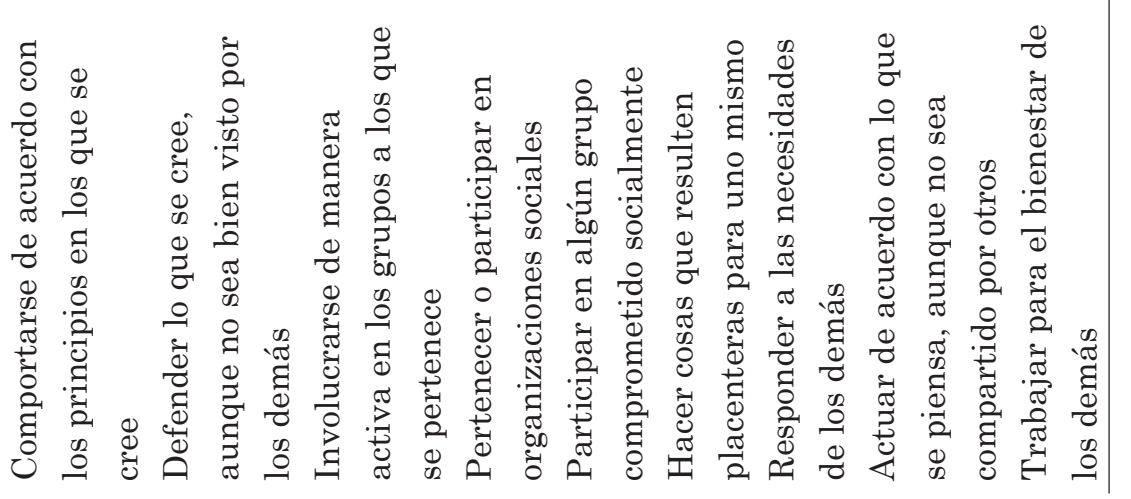




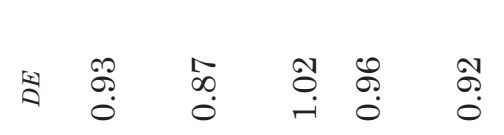

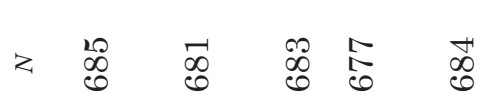

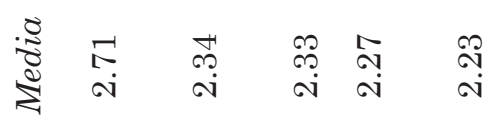

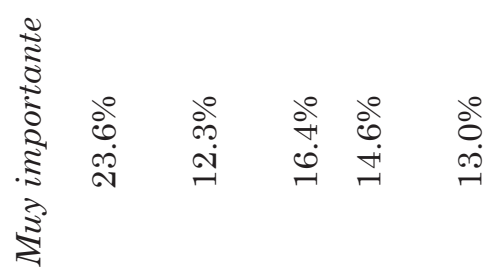

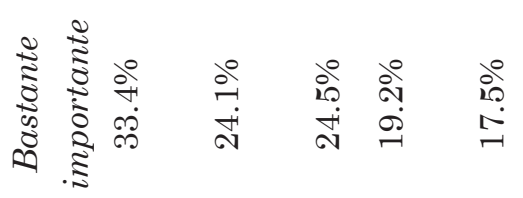

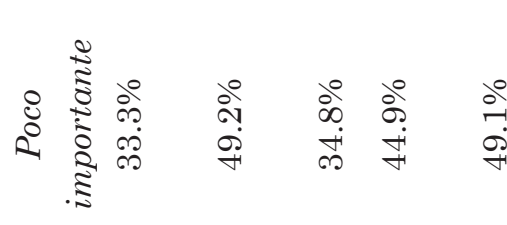

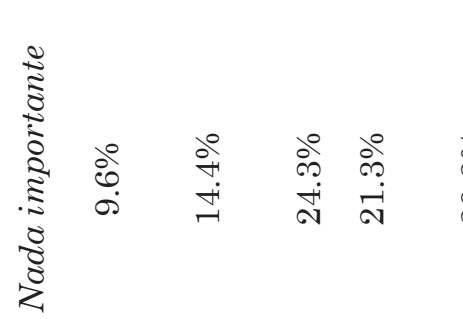

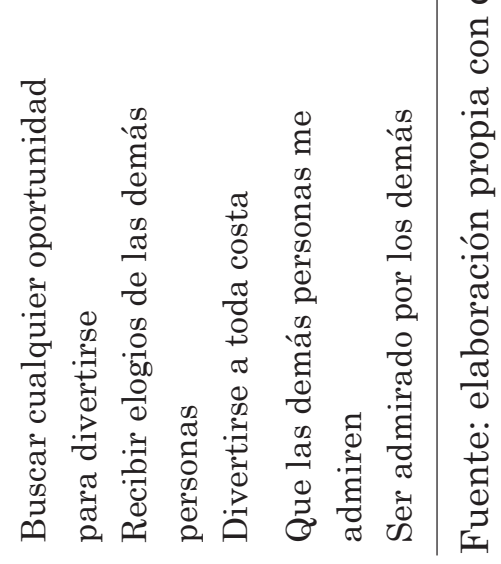


Respecto a diferencias entre características sociodemográficas, no se encontraron significativas por género, aunque los hombres muestran medias más elevadas en valores personales e individualistas (Tabla 9).

Tabla 9. Medias de valores de acuerdo con género

\begin{tabular}{cccc} 
Sexo & $N$ & Media & DE \\
Valores sociales & & & \\
femenino & 460 & 30.04 & 4.134 \\
masculino & 182 & 30.03 & 4.256 \\
Valores personales & & & \\
femenino & 454 & 31.35 & 3.497 \\
masculino & 186 & 31.62 & 3.686 \\
Valores individualistas & & & \\
femenino & 455 & 14.92 & 3.856 \\
masculino & 184 & 15.39 & 3.674 \\
\hline
\end{tabular}

Fuente: elaboración propia con datos de la investigación.

Se encontraron diferencias significativas en las variables de estado civil y ocupación, en específico en los valores individualistas, que son mayores en los solteros $(\mathrm{F}=2.894$, sig. al .05, gl=4) y en los estudiantes ( $\mathrm{F}=2.659$, sig. al .05, gl=5).

Por otro lado, la Tabla 10 muestra las correlaciones encontradas entre los valores y sus diferentes dimensiones y factores y variables como la edad, la escolaridad y la satisfacción vital. Al correlacionar la edad con los valores, se observan algunas correlaciones significativas: positiva con la integridad y negativas con hedonismo, reconocimiento social y, por lo tanto, en el factor valores individualistas, compuesto por estas dimensiones -es decir, a menor edad, mayores valores individualistas-.

La escolaridad, aunque de manera muy baja, se correlaciona significativamente de manera positiva con los valores de honestidad y la sumatoria de valores personales. El caso de la satisfacción vital es interesante ya que casi todas las

\section{6}


sumatorias de valores se correlacionan de manera positiva y significativa, no así las dimensiones relacionadas con los valores individualistas. El estar más satisfecho con su vida eleva los valores sociales y personales.

Tabla 10. Correlaciones entre valores, edad, escolaridad y satisfacción vital

$\begin{array}{cccc} & \text { Edad } & \text { Escolaridad } & \text { Satisfacción } \\ \text { Correlaciones } & r & \text { rho } & \text { vital }\end{array}$

\section{Dimensiones}

Prosocialidad

NS NS $\quad .159 * * *$

Compromiso social

NS NS

$.118^{* *}$

Justicia e igualdad social

NS

NS

$.117^{* *}$

Responsabilidad

Integridad

NS

$.113^{* *}$

Honestidad

NS

Hedonismo

$-.137 * * *$

Reconocimiento social

$-.159 * * *$

$.171^{* * *}$

NS

$.157^{* * *}$

Factores

Valores sociales

Valores personales

$\mathrm{NS}$
$.096^{*}$

NS

$.226 * * *$

NS

NS

NS

$-.108^{* *}$

Valores individualistas

$-.177^{* * *}$

$\begin{array}{cc}\text { NS } & .156^{* * *} \\ .092 * & .230 * * * \\ \text { NS } & \text { NS }\end{array}$

* $\mathrm{p}<.001 ;{ }^{* *} \mathrm{p}<.01 ;{ }^{* * *} \mathrm{p}<.001$.

Fuente: elaboración propia con datos de la investigación.

Por último, los participantes reportaron en un $76 \%$ que volverían a ser voluntarios si se les invitara. Estos sujetos tienen significativamente mayores valores sociales y mayores medias en las dimensiones prosocialidad, compromiso social y responsabilidad (Tabla 11). 
Felipe J. Hevia y Samana Vergara-Lope

Tabla 11. Diferencias en valores entre los que les gustaría ser voluntario nuevamente y los que no

\begin{tabular}{|c|c|c|c|c|c|c|c|c|}
\hline \multirow[b]{3}{*}{ Prosocialidad } & \multicolumn{2}{|c|}{$N$} & \multicolumn{2}{|c|}{ Media } & \multicolumn{2}{|c|}{$D E$} & \multirow[t]{2}{*}{$t$} & \multirow{2}{*}{$g l$} \\
\hline & No & $S i$ & No & $S i$ & No & Sí & & \\
\hline & 26 & 602 & 8.92 & 9.71 & 1.787 & 1.674 & $-2.349 *$ & 626 \\
\hline $\begin{array}{l}\text { Compromiso } \\
\text { social }\end{array}$ & 26 & 609 & 8.15 & 9.84 & 1.974 & 1.787 & $-4.699 * *$ & 633 \\
\hline $\begin{array}{l}\text { Justicia e } \\
\text { igualdad social }\end{array}$ & 26 & 607 & 10.31 & 10.66 & 1.463 & 1.407 & NS & \\
\hline Responsabilidad & 26 & 600 & 10.04 & 10.67 & 1.483 & 1.494 & $-2.099 *$ & 624 \\
\hline Integridad & 25 & 604 & 10.00 & 9.84 & 1.683 & 1.668 & NS & \\
\hline Honestidad & 25 & 606 & 10.68 & 10.96 & 1.249 & 1.264 & NS & \\
\hline Hedonismo & 25 & 603 & 8.72 & 8.24 & 2.170 & 2.226 & NS & \\
\hline $\begin{array}{l}\text { Reconocimiento } \\
\text { social }\end{array}$ & 26 & 592 & 6.19 & 6.86 & 1.767 & 2.377 & NS & \\
\hline Valores sociales & 26 & 588 & 27.38 & 30.23 & 4.090 & 4.047 & $-3.502^{* *}$ & 612 \\
\hline $\begin{array}{l}\text { Valores } \\
\text { personales }\end{array}$ & 24 & 587 & 30.75 & 31.49 & 3.554 & 3.420 & NS & \\
\hline $\begin{array}{l}\text { Valores } \\
\text { individualistas }\end{array}$ & 25 & 583 & 14.80 & 15.05 & 2.944 & 3.897 & NS & \\
\hline
\end{tabular}

Fuente: elaboración propia con datos de la investigación.

En resumen, los reactivos más altos son los relacionados a la dimensión de honestidad y al factor valores personales, y los más bajos a la dimensión de reconocimiento social $\mathrm{y}$ al factor valores individualistas. Aunque son bajas, las correlaciones significativas indican que los voluntarios más jóvenes presentan una tendencia más hacia los valores individualistas que a los personales y sociales, lo que coincide con el hecho de que los valores individualistas son significativamente mayores en los solteros y en los estudiantes. Los valores personales, por su parte, aumentan al incrementarse la escolaridad. De esta forma, la satisfacción vital y los valores se correlacionan de manera positiva y significativa, con excepción de los valores individualistas, 
esto es, al aumentar la satisfacción en la vida aumentan los valores sociales y personales, y viceversa.

\section{Conclusiones}

Los resultados obtenidos permiten ordenar las conclusiones en cuatro puntos relacionados con las agendas académica, política y educativa discutidas en la introducción. Un primer punto discute la agenda académica, debate algunas similitudes y diferencias respecto a la información disponible y señala las particularidades del caso analizado. Un segundo punto retoma la agenda política y propone articular los resultados obtenidos con una agenda de promoción y reconocimiento de la acción voluntaria en México. Un tercer punto discute los resultados y su relevancia dentro de la agenda educativa. Por último, se propone una agenda de investigación futura que toma en cuenta los hallazgos presentados.

En relación con el primer punto, el caso seleccionado permite conocer con mayor detalle las características de ciudadanos que deciden participar en un proyecto educativo. Así, se puede concluir que los voluntarios del proyecto MIA son principalmente jóvenes estudiantes universitarios (y en menor cantidad empleados y desempleados), solteros y mayormente mujeres. Se trata de voluntarios infrecuentes, puesto que dedican pocos días al año al trabajo solidario; participan en campañas y causas, en este caso, de temática educativa; y también son instrumentales, porque buscan nuevas experiencias, formación, ocupar el tiempo libre y ejercer la profesión.

También es un hallazgo que los voluntarios estudiados tienen alta satisfacción vital y mayores valores personales (honestidad, responsabilidad e integridad) y sociales (justicia e igualdad social, compromiso social y prosocialidad) que individualistas (hedonismo y reconocimiento social). La dimensión más alta reportada por ellos fue la honestidad 
y la más baja el reconocimiento social. La mayoría de los participantes volvería a participar como voluntario, y los que refieren esto tienen valores sociales más altos.

Estos resultados coinciden con otras investigaciones empíricas respecto a la relación recíproca entre los valores sociales y el voluntariado (Gallarza et al., 2016; Guzmán, Carvajal, Villablanca, y Espinoza, 2017). Al buscar relaciones entre valores y satisfacción entre los voluntarios, se observa una baja pero clara relación entre los valores sociales y personales y la satisfacción de vida, esto es, al aumentar los valores sociales y personales aumenta la satisfacción con su vida, y viceversa.

En este sentido, a pesar de no tener datos directos que comprueben la hipótesis de que el trabajo voluntario promueve los valores personales y prosociales $-\mathrm{y}$, como consecuencia, la satisfacción vital-, la presencia de la relación entre satisfacción de vida y valores sociales y personales, y el hecho de que estos tres aspectos sean elevados en la muestra de voluntarios, hace pensar que probablemente al promover valores personales y sociales sea más posible aumentar la participación de las personas en el voluntariado, y que eso estará vinculado con la satisfacción de vida de los que participen en él-directamente proporcional a sus valores personales y sociales, como ya se vio-.

Asimismo, si se promueve el voluntariado como actividad entre los jóvenes, se estarán promoviendo sus valores sociales y personales y, por lo tanto, se aumentará su satisfacción vital. Esto coincide con otras investigaciones que enfatizan la relación entre voluntariado y bienestar social, en particular en los jóvenes (Laca Arocena, Rodríguez, y Sánchez, 2013).

En segundo lugar, en relación con la agenda política de promoción y reconocimiento al trabajo voluntario, el caso analizado entrega algunos hallazgos que pueden resultar útiles para fomentar el voluntariado. En este sentido, los 
hallazgos respecto a la importancia de los valores sociales para los voluntarios sugieren la importancia de promover programas sociales y educativos enfocados a ampliar los valores personales como honestidad, responsabilidad e integridad y los valores sociales como justicia e igualdad social, compromiso social y prosocialidad entre los jóvenes, lo que aporte a su satisfacción vital.

De igual manera, desde la perspectiva instrumental del trabajo voluntario identificada, ganar experiencia resulta un aprendizaje central y un elemento motivador para participar en acciones voluntarias (Haski-Leventhal et al., 2019), y posibilita pensar un potencial de fomento al trabajo voluntario en centros de enseñanza de educación media superior y superior y organizaciones sociales y de base -como sindicatos, organizaciones campesinas y ejidales, comités de mejora de las localidades y grupos deportivos-, donde se podría fomentar la experiencia de y satisfacción a partir del trabajo voluntario, tal como reseña la literatura en otras latitudes (Gaete Quezada, 2015; Gazo, 2018).

Tomando en cuenta el contexto político mexicano de finales de la década de 2010, el diseño de nuevas políticas públicas enfocadas a los jóvenes que se promueven bajo la administración del presidente Andrés Manuel López Obrador en el Poder Ejecutivo federal, como el programa Jóvenes Construyendo Futuro, de la Secretaría del Trabajo y Previsión Social (2019), o los diversos programas de la Secretaría de Bienestar Social, como las becas Benito Juárez García, o incluso el Censo del Bienestar (Secretaría de Bienestar, 2019), resulta en ventanas de oportunidad inmejorables para fomentar el trabajo voluntario, lo que incrementa a su vez los niveles de satisfacción vital y promueve valores sociales y personales dentro de amplios sectores juveniles. Todo esto representa acciones de suma positiva (ganar-ganar), puesto que al promover el trabajo voluntario entre jóvenes se fomenta una ciudadanía más solidaria y con 
niveles más altos de satisfacción sobre su propia vida, lo que redunda en mayor bienestar social.

En tercer lugar, respecto a la discusión entre los resultados y la agenda educativa, el caso seleccionado y las valoraciones expresadas en las narraciones de los voluntarios permiten sostener que el tipo de causa que representa la educación es un campo de política fértil para motivar las actividades de voluntariado. El análisis cualitativo pudo mostrar que el trabajo voluntario aportó experiencia personal y profesional; conocimientos sobre el nivel insuficiente de los aprendizajes básicos de niños y niñas; y aprendizajes sobre la problemática infantil. Por ello, se puede concluir que el trabajo voluntario sensibilizó y motivó a sus participantes respecto de la problemática educativa en México.

Estos resultados son coherentes con los últimos datos que presenta la ENSAV, en el sentido de que la temática educativa desata un especial interés para la participación voluntaria de los ciudadanos y que se detecta una energía en potencia en torno a este tema (Butcher y Verduzco, 2016). Las narrativas de los voluntarios mostraron altos niveles de compromiso con la educación como una temática que despierta el interés y que facilita la participación en acciones voluntarias. Cabe señalar que, además de las actividades solidarias más comunes que desempeñan los mexicanos (en específico, los padres y madres de familia) en torno a la educación, como la colaboración en la escuela a la hora de la entrada o la salida, o el mantenimiento de los inmuebles y mobiliario (Butcher y Verduzco, 2016), los resultados permiten pensar que existen otras formas de involucramiento ciudadano por medio del trabajo voluntario. Como el caso analizado muestra, se pueden encontrar oportunidades para realizar acciones voluntarias y echar a andar su energía vinculada directamente en actividades de evaluación de los aprendizajes básicos, por medio de instrucciones claras y tareas específicas.

\section{2}


Este tipo de acción voluntaria es fundamental para aumentar la participación de los ciudadanos en temas educativos, pero también para que colaboren en un cambio de paradigma que permita posicionar a los aprendizajes en el centro de la discusión educativa en general y facilitar el involucramiento de los ciudadanos, algo fundamental para mejorar la educación, según la evidencia disponible (World Bank, 2018).

La experiencia personal que genera visitar hogares durante un día, en que se conocen muchos niños que van a la escuela pero no comprenden bien lo que leen, o saben sumar pero no restar, como se mencionó con anterioridad, es una de las que los voluntarios remiten como dadora de aprendizajes más significativos en su participación en este proyecto y motivadora para querer hacer algo más por la educación. Esta situación la comparten otros proyectos educativos que trabajan con voluntarios en el sur global (Banerji, Bhattacharjea, y Wadhwa, 2013; Mugo, Ruto, Nakabugo, y Mgalla, 2015).

En efecto, el tema de la calidad y la evaluación educativa es una constante en la coyuntura nacional, y en particular en el sureste del país. Las instituciones y personas que se han involucrado en la medición de aprendizajes tienen un interés particular en la educación de los niños y adolescentes, interés que se refuerza cuando se piensa en los propios hijos, hermanos, vecinos y en la necesidad urgente de contribuir de alguna manera para lograr una mejora sustantiva en las habilidades básicas, como la lectura y las matemáticas.

Es digno de resaltar el hecho de que un alto porcentaje de los voluntarios de MIA estuvo integrado por personas jóvenes, quienes tienen aún fresca la percepción de la educación que han recibido en las escuelas de educación básica y que coinciden en el deseo de aportar su granito de arena para que la educación mejore. Así, en un contexto, como el mexicano, 
donde el trabajo voluntario es poco institucionalizado, la experiencia de MIA resulta gratificante y genera confianza respecto a la participación de la sociedad civil en la solución de los problemas que afectan su entorno.

Por último, respecto de la agenda futura de investigación, los hallazgos indican, por un lado, la necesidad de complementar los resultados con un seguimiento más profundo de los efectos en el corto y mediano plazo que estas acciones voluntarias podrían tener. Por ejemplo: ¿el iniciar acciones infrecuentes e instrumentales predice una participación voluntaria más regular e intensiva? ¿La participación en acciones voluntarias mejora las habilidades socioemocionales y las nuevas habilidades blandas necesarias para la inclusión laboral en el mediano plazo? ¿Estas acciones tienen algún tipo de efecto en el entorno inmediato -familia o amistades- de los voluntarios?

Por otro lado, este estudio se limita a voluntarios, lo que permite valorar la relevancia de generar investigación comparada con otras poblaciones, incluyendo jóvenes sin experiencia voluntaria y voluntarios con otras características -como la frecuencia, orientación o tipo de acción voluntaria-. En este sentido, los resultados de esta investigación concluyen que los instrumentos para medir satisfacción vital y valores mostraron confiabilidad aceptable para población mexicana entre quince y setenta y un años y con sólo cuatro opciones de respuesta, lo que facilita su uso para fines comparativos, tanto para la investigación sobre voluntariado como para otros contextos.

De igual manera, se propone como agenda de investigación futura hacer comparaciones de satisfacción de vida y valores en personas no voluntarias, así como medir la satisfacción de vida y los valores antes y después de la experiencia de voluntariado. Se sugiere integrar mayor investigación sobre la importancia de los contextos y las causas de la participación voluntaria para comprender 
mejor, y así reconocer, valorar y fomentar, el trabajo voluntario en México.

Alcott, B., Rose, P., Sabates, R., Luisa Alonso, M., y Cherfils, M. (20I8). Experience and lessons of learning intervention programmes across the PAL Network members. Recuperado de https://zenodo.org/record/19949/9

Antolín, L., Oliva, A., Pertegal, M. A., y López, A. M. (20I I). Desarrollo y validación de una escala de valores para el desarrollo positivo adolescente. Psicothema, 23(I), 153-159. Recuperado de http://www.psicothema.com/ psicothema.asp?id=3864

Ariza-Montes,A.,Tirado-Valencia, P., y Fernández-Rodríguez, V. (2017). Valores humanos y voluntariado. Un estudio en personas mayores. Intangible capital, I3(2), 253-28I. doi https://doi.org/I0.3926/ic.717

Asamblea General de las Naciones Unidas (2015). El camino hacia la dignidad para 2030: acabar con la pobreza y transformar vidas protegiendo el planeta. Informe de síntesis del secretario general sobre la agenda de desarrollo sostenible después de 2015. Nueva York:Asamblea General de las Naciones Unidas.

Azzollini, S., Pupko, V. B., Becerra, L., y Vidal, V. (2017). Perfil de voluntarios para la asistencia en emergencias $y$ catástrofes: la empatía y el entrenamiento en primera atención psicológica. Anuario de investigaciones, XXIV, I 37 143. Recuperado de http://ppct.caicyt.gov.ar/index.php/ anuinv/article/view/II 252

Bailón, S. M., Pérezgrueso, A. J. B., y Arceiz, F. J. L. (2017). ¿Son los voluntarios un recurso sustitutivo de los trabajadores? Una aproximación desde la economía social aragonesa. REVESCO. Revista de estudios cooperativos, (123), | 43-173. doi https://doi.org/I0.5209/REVE.549|7

Banerjee,A., Banerji, R., Berry,J., Duflo, E., Kannan, H., Mukerji, S., yWalton, M. (20I7). From Proof of Concept to Scala- 
Bibliografía ble Policies: Challenges and Solutions, with an Application. Journal of Economic Perspectives, 3 I (4), 73- I02. doi https://doi.org/ / 0.1257/jep.3 I.4.73

Banerji, R., Bhattacharjea, S.,yWadhwa,W. (2013).TheAnnual Status of Education Report (ASER). Research in Comparative and International Education, 8(3), 387. doi https://doi. org/ I 0.2304/rcie.20I3.8.3.387

Butcher,J.(2008a). Marco conceptual de la acción solidaria y voluntaria. En J. Butcher (Ed.), México solidario: participación ciudadana y voluntariado (pp. 17-56). México: CEMEFI, Instituto Mora, Limusa.

Butcher, J. (Ed.) (2008b). México solidario: participación ciudadana y voluntariado. México: CEMEFI, Instituto Mora, Limusa.

Butcher,J.(Ed.) (2009). Mexican Solidarity: Citizen Participation and Volunteering. Nueva York: Springer.

Butcher,J. (20I4). Tercer sector y desarrollo en México. En A. Girón (Ed.), Del "vivir bien"al "buen vivir": entre la economía feminista, la filantropía y la migración. Hacia la búsqueda de alternativas (pp. 9I-II2). México: IIE, UNAM. Recuperado de http://www.probdes.iiec.unam.mx/coleccion_de_libros/ pdf/delvivirbien/05_Butcher.pdf

Butcher, J., y Verduzco, G. (2016). Acción voluntaria y voluntariado en México. México: Fundación Telefónica.

Cabrera-Darias, M. E., y Marrero-Quevedo, R. J. (20I5). Motivos, personalidad y bienestar subjetivo en el voluntariado. Anales de psicología, 3 I (3), 79I-80 I. doi https:// doi.org/10.6018/analesps.31.3.18092I

Centro Mexicano para la Filantropía (2013). Encuesta Nacional de Solidaridad y Acción Voluntaria, ENSAV, 20 I 2. Resultados preliminares. México: CEMEFI.

Cnaan, R.A., Handy, F., yWadsworth, M.(1996). Defining who is a Volunteer: Conceptual and Empirical Considerations. Nonprofit and Voluntary Sector Quarterly, 25(3), 364-383. doi https://doi.org/ I 0.1 I 77/0899764096253006

\section{6}


Colectivo IOE (1990). Participación ciudadana y voluntariado Bibliografía social. Documentación social, 80, I59-170. Recuperado de https://www.colectivoioe.org/

Colectivo IOE (2002). Análisis ideológico y motivacional del voluntariado español. Madrid: Colectivo IOE.

Dutt, S. C., Kwauk, C., y Robinson, J.P. (2016).Pratham's Read India Program. Taking small steps toward learning at scale. Washington: Center for Universal Education, Brookings Institution. Recuperado de https://www.brookings.edu/ wp-content/uploads/2016/07/FINAL-Read-India-CaseStudy.pdf

Eliasoph, N. (20I3). The Politics of Volunteering. Londres: Polity. Espinosa Rodríguez, E., Mayoral Sánchez, E. G., y Laca Arocena, F. A. (20I3). Altruismo y bienestar social en la explicación de voluntariado en estudiantes mexicanos de bachillerato y licenciatura. Psicología iberoamericana, 2 I (2), 85-95. Recuperado de http://revistas.ibero.mx/ psicologia/uploads/volumenes/9/pdf/PSICOLOGIA_IBEROAMERICANA_2I_2.pdf

Fernández, J. S. (2004). La cultura política y democrática del voluntariado social. Revista del Ministerio de Trabajo e Inmigración, (55), 27-44. Recuperado de http://www. mitramiss.gob.es/es/publica/pub_electronicas/destacadas/revista/numeros/55/Est02.pdf

Gaete Quezada, R. (20I5). El voluntariado universitario como ámbito de aprendizaje, servicio y emprendimiento social: un estudio de caso. Última década, 23(43), 235-260. doi https://doi.org/I0.4067/S07 I 8-223620I5000200009

Gallarza, M. G. (20 I4).Voluntary sector. En J. Jafari, y H. Xiao (Eds.), Encyclopedia ofTourism (pp. I-2). Nueva York:Springer International Pub. doi https://doi.org// 0.1007/9783-319-01669-6_216-I

Gallarza, M. G., Arteaga-Moreno, F., Servera-Francés, D., y Fayos-Gardó, T. (2016). Participar como voluntario en eventos especiales: comparación entre el valor esperado 
y percibido. Innovar. Revista de ciencias administrativas y sociales, 26(59), 47-60. doi https://doi.org//0.15446/ innovar.v26n59.54322

García, S., Hevia, F. J., Layton, M. D., Verduzco, M. I., Santos, M., y Rosas, A. P. (20I0). Leyes estatales de fomento a las actividades de las organizaciones de la sociedad civil. Análisis y recomendaciones. México: Incide Social, ITAM, Alternativas y Capacidades.

García Roca, X. (200I). El voluntariado en la sociedad de bienestar. Documentación social, I 22, 15-39. Recuperado de http://participacionsocial.aytosalamanca.es/es/agenciadevoluntariado/docs/EL_VOLUNTARIADO_EN_LA_ SOCIEDAD_DE_BIENESTAR.PDF

Gazo,J.M. (2018). Experiencia de voluntarios universitarios nicaragüenses: de la mano con la antropología social. Raíces. Revista nicaragüense de antropología, 2(3), 89-97. doi https://doi.org// 0.5377/raices.v2i3.6902

Gonçalves, T. D., Grzybovski, D., Mozzato, A. R., y Toebe, C. S. (2017). Contradições no agir do voluntário nas organizações da sociedade civil: ensaio teórico à luz da sociologia pragmática francesa. Cadernos EBAPE.BR, I 5(4), 900-9/3. doi https://doi.org// 0.1590/I679-395 I55047

Guzmán, C. A., Carvajal, S. A., Villablanca, E. C., y Espinoza, M. C. C. (20I7). Voluntariado juvenil: Factores de permanencia en experiencias de intervención en infancia. Opción, 33(82), 214-238. Recuperado de https://dialnet. unirioja.es/servlet/articulo?codigo $=6233625$

Haski-Leventhal, D., Oppenheimer, M., Holmes, K., Lockstone-Binney, L., Alony, I., y Ong, F. (20I9). The conceptualization of volunteering among non-volunteers: using the net-cost approach to expand definitions and dimensions of volunteering. Nonprofit and Voluntary Sector Quarterly, 48(2), 30S-5IS. doi https://doi. org/I 0.1 I 77/08997640 I8768078 
Hernández López, R.A., y Valverde Hernández, C. J. (20I8).

Bibliografía Una mirada alternativa a la migración: el voluntariado juvenil como forma de participación social. LiminaR. Estudios sociales y humanísticos, I 6(2), 72. doi https://doi. org/ 10.29043/liminar.v I 6i2.598

Ho, M., y O'Donoghue, S. (20I4). Volunteer stereotypes, stigma, and relational identity projects. European Journal of Marketing, 48(5/6), 854-877. doi https://doi. org/ I 0. I I08/EJM-I I-20 I I-0637

Huebner, E. S. (I99I). Escala para la evaluación de la satisfacción vital. En A. Oliva (Coord.), Instrumentos para la evaluación de la salud mental y el desarrollo positivo adolescente y los activos que lo promueven (pp. 82-92). Andalucía: OBEMEDIA.

Independent Sector, y Voluntarios de las Naciones Unidas (200I).La medición del servicio voluntario, una guía práctica. Recuperado de http://www.boluntariotza.net/comun/ biblioteca/la_medicion_del_servicio_voluntariado_ guia_practica.pdf

Instituto Nacional Electoral (20I4). Informe país sobre la calidad de la ciudadanía en México. Recuperado de http:// www.ine.mx/archivos2/portal/DECEYEC/EducacionCivica/informePais/

Instituto Nacional de Estadística y Geografía (20 I4). Sistema de Cuentas Nacionales de México. Cuenta satélite de las instituciones sin fines de lucro de México 2012. Preliminar año base 2008. Recuperado de http://internet.contenidos.inegi.org.mx/contenidos/productos//prod_serv/ contenidos/espanol/bvinegi/productos/derivada/satelite/ sin_fines_lucro/20I2_preli/70282506 I685.pdf

Izquieta, J. L., y Callejo, J. (1999). Los nuevos voluntarios: naturaleza y configuración de sus iniciativas solidarias. Reis, (86), 95- I 26. doi https://doi.org/ I0.2307/40 I 84 I 47 Khasanzyanova,A. (2017). How volunteering helps students to develop soft skills. International Review of Education, 
Bibliografía
63(3), 363-379. doi https://doi.org/|0.1007/s III59017-9645-2

Laca Arocena, F. A., Rodríguez, E. de J. E., y Sánchez, E. G. M. (20I3). Exploración de un modelo estadístico de voluntariado estudiantil en mexicanos. Ciencia ergo-sum, 20(3), 193-200. Recuperado de https://cienciaergosum. uaemex.mx/article/view/7032

Legislatura Querétaro (2017). Iniciativa de Ley del Voluntariado del Estado de Querétaro. Querétaro: LVIII Legislatura Estado de Querétaro, Comisión de Participación Ciudadana.

Lewis, D. (1999). International Perspectives on Voluntary Action: Reshaping the Third Sector. Canadá: Earthscan.

Martinic, S. (2006). El estudio de las representaciones y el análisis estructural de discurso. En M. Canales (Ed.), Metodologías de investigación social: introducción a los oficios (pp. 299-320). Santiago: Lom Ediciones.

Mateo Pacheco, G. (2017). Ingeniería en comunicación social del voluntariado en organizaciones de la sociedad civil en Puebla. Razón y palabra, 2 I (96), I 46-I62.

Millán, A. N. (20/3). Una aproximación al voluntariado desde las unidades de información. Anales de documentación, /6(1). doi https://doi.org//0.6018/analesdoc.|6.1.15279|

Mugo,J. K., Ruto, S. J., Nakabugo, M. G., y Mgalla, Z. (20I5).A Call to Learning Focus in EastAfrica:Uwezo's Measurement of Learning in Kenya, Tanzania and Uganda. Africa Education Review, I2(I), 48-66. doi https://doi.org/I0.I 080/I8I46627.20I5.1036564

Munene, I. I. (Ed.) (2016). Achieving Education for All:Dilemmas in System-wide Reforms and Learning Outcomes in Africa. Londres: Lexington Books.

Muñoz, C., y Vázquez, V. (20I2). El Estado neoliberal y las mujeres indígenas. Un estudio de caso de la Sierra Negra de Puebla. Espiral estudios sobre Estado y sociedad, 19(53), 
19-|2|. Recuperado de http://www.espiral.cucsh.udg. Bibliografía mx/index.php/EEES/article/view/299

Naciones Unidas (200I). El papel del voluntariado en la promoción del desarrollo social. Recuperado de http://www. worldvolunteerweb.org/fileadmin/docs/old/html/2002/ csd_document_span.htm

Pérez, J.A. (2015). Marco jurídico del voluntariado en México. México: Universidad Anáhuac México Norte.

Piedimonte, F.R.,y Depaula, P.D. (2018). Motivación y valores relativos al trabajo en bomberos voluntarios y remunerados argentinos. Liberabit. Revista de psicología, 24(2), 277-294. doi https://doi.org//0.24265/liberabit.2018. v24n2.08

Rochester, C., Paine,A. E., Howlett, S.,y Zimmeck, M. (20 I0). Volunteering and Society in the 2 Ist Century. Nueva York: Springer.

Ruiz, E.M.(2016). El voluntariado en España: situación actual, tendencias y retos. La razón histórica, (33), II 0-I 29. Recuperado de https://www.revistalarazonhistorica. com/app/download/ I0670982098/LRH+33.7.pdf?$\mathrm{t}=|4698| \mid 255 \&$ mobile $=\mid$

Secretaría de Bienestar (2019). Becas Benito Juárez García. Recuperado de http://becasbenitojuarez.mx/

Secretaría del Trabajo y Previsión Social (2019). Programa Jóvenes Construyendo el Futuro-Desarrollando el talento. México. Recuperado de https://jovenesconstruyendoelfuturo.stps.gob.mx/

Serna, M. G. (2010). La diversidad y el contexto cambiante del voluntariado en México. Espiral estudios sobre Estado y sociedad, I 6(47), I I I - 72. Recuperado de http://www. espiral.cucsh.udg.mx/index.php/EEES/article/view/I 455 Soto-Lagos, R., Constela, C.V., y Vergara, O. F. (20I7). Voluntariado y deporte: análisis de factores en la incidencia de la satisfacción de los/as voluntarios/as de los Juegos Suramericanos Santiago de Chile 20I4. Revista brasileira 
Bibliografía de ciências do esporte, 39(2), 191-198. doi https://doi. org/I0.10I6/j.rbce.2016.09.00 I

Suárez, H.J.(Ed.) (2008). El sentido y el método:sociología de la cultura y análisis de contenido. México: IIS-UNAM, Colmich. Subirats, J. (200I). Sociedad civil y voluntariado: responsabilidades colectivas y valores públicos en España. Documentación social, I 22,4 I-66. Recuperado de http:// participacionsocial.aytosalamanca.es/es/agenciadevoluntariado/docs/EL_VOLUNTARIADO_EN_LA_SOCIEDAD_DE_BIENESTAR.PDF

Verduzco, G. (2008). Las acciones solidarias en México (análisis de la Encuesta Nacional de Solidaridad y Acción Voluntaria). En J. Butcher (Ed.), México solidario:participación ciudadana y voluntariado (Pp.57-I0I). México: CEMEFI, Instituto Mora, Limusa.

Wilson, H. M. (26 de octubre de 2018). How Civil Society Can Supply Rigorous Data for the SDGs:The Citizen-Led Assessment Approach. Recuperado de https://sdg.uis.unesco. org/20 I8/ 10/26/how-civil-society-can-supply-rigorousdata-for-the-sdgs-the-citizen-led-assessment-approach/ Wilson, J. (2000). Volunteering. Annual Review of Sociology, 26, 215-240. doi https://doi.org/10.1 146/annurev. soc.26.1.215

Wilson, J. (20I2). Volunteerism Research: A Review Essay. Nonprofit and Voluntary Sector Quarterly, 4 I (2), I 76-2I 2. doi https://doi.org/ I 0. I I77/08997640 I I 434558

World Bank (2018). Learning to realize education's promise. Washington:The World Bank.

Zurita, U. (20I3). Paradojas y dilemas de la participación social en la educación básica en México.Apuntes, XL(72), 85-I I 5. Recuperado de https://revistas.up.edu.pe/index. php/apuntes/article/view/676/675 